\title{
An activated Th17-prone T cell subset involved in chronic graft-versus- host disease sensitive to pharmacological inhibition
}

Edouard Forcade, ${ }^{1,2,3,4}$ Katelyn Paz, ${ }^{5}$ Ryan Flynn, ${ }^{5}$ Brad Griesenauer, ${ }^{6,7,8,9}$ Tohti Amet, ${ }^{6,7,8,9}$ Wei Li, $, 6,7,8,9$ Liangyi Liu, ${ }^{6,7,8,9}$ Giorgos Bakoyannis, ${ }^{10}$ Di Jiang, ${ }^{11}$ Hong Wei Chu, ${ }^{11}$ Mercedes Lobera, ${ }^{12}$ Jianfei Yang, ${ }^{12}$ David S. Wilkes, ${ }^{13}$ Jing Du, ${ }^{5}$ Kate Gartlan, ${ }^{14}$ Geoffrey R. Hill, ${ }^{14}$ Kelli P.A. MacDonald, ${ }^{14}$ Eduardo L. Espada, ${ }^{1,2}$ Patrick Blanco, ${ }^{3}$ Jonathan S. Serody, ${ }^{15}$ John Koreth, ${ }^{1,2}$ Corey S. Cutler, ${ }^{1,2}$ Joseph H. Antin,, ${ }^{1,2}$ Robert J. Soiffer, ${ }^{1,2}$ Jerome Ritz, ${ }^{1,2}$ Sophie Paczesny, ${ }^{6,7,8,9}$ and Bruce R. Blazar

'Division of Hematologic Malignancies and Department of Medical Oncology, Dana-Farber Cancer Institute, Boston, Massachusetts, USA. ${ }^{2}$ Harvard Medical School, Boston, Massachusetts, USA. ${ }^{3}$ Immunoconcept, CNRS UMR 5164, Bordeaux University, Bordeaux, France. ${ }^{4}$ Department of Hematology and Cell Therapy, University Hospital, Bordeaux, France. ${ }^{5}$ Division of Blood and Marrow Transplantation, University of Minnesota, Minneapolis, Minnesota, USA. ${ }^{6}$ Department of Pediatrics, Indiana University School of Medicine, Indianapolis, Indiana, USA. ${ }^{7}$ Herman B. Wells Center for Pediatric Research, ${ }^{8}$ Department of Microbiology and Immunology, and ${ }^{9}$ Melvin and Bren Simon Cancer Center, Indiana University School of Medicine, Indianapolis, Indiana, USA. ${ }^{10}$ Department of Biostatistics, Indiana University Fairbanks School of Public Health and School of Medicine, Indiana, USA. "National Jewish Health, Denver, Colorado, USA ${ }^{12}$ ClaxoSmithKline, Cambridge, Massachusetts, USA. ${ }^{13}$ Dean, University of Virginia, School of Medicine, Charlottesville, Virginia, USA. ${ }^{14}$ QIMR Berghofer Medical Research Institute, Brisbane, Queensland, Australia. ${ }^{15}$ Lineberger Comprehensive Cancer Center and Department of Microbiology and Immunology, University of North Carolina at Chapel Hill, Chapel Hill, North Carolina, USA.

Authorship note: EF, KP, and RF contributed equally as first authors. JR, SP, and BRB contributed equally as senior authors.

Conflict of interest: JY and ML are employees of Tempero Pharmaceuticals a company of GSK that owns TMP778.

Submitted: December 9, 2016

Accepted: May 16, 2017

Published: June 15, 2017

\section{Reference information:} JCI Insight. 2017;2(12):e92111. https:// doi.org/10.1172/jci.insight.92111.
Chronic graft-versus-host disease (cGvHD) remains a major complication of allogeneic stem cell transplantation requiring novel therapies. CD146 and CCR5 are expressed by activated T cells and associated with increased $\mathrm{T}$ cell migration capacity and Th17 polarization. We performed a multiparametric flow cytometry analysis in a cohort of 40 HSCT patients together with a cGvHD murine model to understand the role of CD146-expressing subsets. We observed an increased frequency of CD146+ CD4 T cells in the 20 patients with active CGvHD with enhanced ROR $\gamma t$ expression. This Th17-prone subset was enriched for cells coexpressing CD146 and CCR5 that harbor mixed Th1/Th17 features and were more frequent in cGvHD patients. Utilizing a murine CGvHD model with bronchiolitis obliterans (BO), we observed that donor T cells from CD146-deficient mice versus those from WT mice caused significantly reduced pulmonary cGvHD. Reduced cGvHD was not the result of failed germinal center B cell or T follicular helper cell generation. Instead, CD146-deficient T cells had significantly lower pulmonary macrophage infiltration and T cell CCR5, IL-17, and IFN- $\gamma$ coexpression, suggesting defective pulmonary end-organ effector mechanisms. We, thus, evaluated the effect of TMP778, a small-molecule ROR $\gamma t$ activity inhibitor. TMP778 markedly alleviated CGvHD in murine models similarly to agents targeting the Th17 pathway, such as STAT3 inhibitor or IL-17-blocking antibody. Our data suggest CD146-expressing T cells as a cGvHD biomarker and suggest that targeting the Th17 pathway may represent a promising therapy for CGvHD.

\section{Introduction}

Over the decades, improvements have been made in acute graft-versus-host disease (aGvHD) prevention. In contrast, chronic GvHD (cGvHD), which is often preceded by a GvHD, continues to be a significant cause of morbidity and mortality, affecting an estimated $50 \%$ of allogeneic hematopoietic stem cell 
transplantation (HSCT) patients $(1,2)$. Efforts have been made to characterize proteomic and cellular biomarkers to better define disease severity, predict therapeutic responses, and improve our understanding of $\mathrm{cGvHD}$ pathogenesis (3-7).

Donor T effector cells (Teffs) have been shown to mediate alloreactivity toward recipient tissue in both human and mice $(2,8,9)$ and are required elements of aGvHD and cGvHD generation. Both in vitro or in vivo $\mathrm{T}$ cell depletion have reduced but not eliminated $\mathrm{CGvHD}$ incidence, and both can be associated with increased infections and malignancy recurrence as complications. Offsetting GvHD-causing Teffs are regulatory mechanisms that serve to dampen the immune destructive responses that can harm the organism. These include cell-surface molecules such as coinhibitory receptors; metabolic control switches such as the indoleamine 2,3-dioxygenase tryptophan catabolic pathway; and cellular mechanisms such as Tregs. Relevant to cGvHD in patients, we previously showed that patients developing cGvHD presented altered Treg homeostasis with quantitative deficiency (5). Strategies to expand Tregs in vivo were efficient at reducing but not uniformly eliminating disease severity (10). Similarly, we observed abnormal homeostasis and chronically activated B cells $(6,11)$, offering the possibility to deplete or target them (12-14). Thus, approaches to be used in combination with Treg augmentation would be desirable. Identifying a new Teff cell involved in the pathogenesis of the disease would be a key step forward to develop prophylactic, therapeutic, and prognostic means of reducing the consequences of $\mathrm{CGvHD}$ in patients.

GvHD-causing Teffs can be contained within Th cell subsets that have been progressively defined according to the expression of surface markers, activation molecules, and chemokine receptors and their capacity to secrete cytokines. Nomenclature defining Th polarization (Th1, Th2, Th9, Th17, Th22, etc.) is expanding with the further complexity that Th cells maintain a degree of plasticity, being able to convert from one subset to another (15). The Th17 subset is defined according to the expression of RAR-orphan receptor $\gamma$ transcription factor $(\mathrm{ROR} \gamma \mathrm{t})(16)$ and the capacity to secrete IL-17 upon stimulation. In addition, different surface markers have been described, such as chemokine receptor 6 (CCR6), CD161, CCR4, IL-23R, and CD5L to characterize the Th17 subset $(17,18)$. Several studies have attempted to decipher the role of Th17 in aGvHD $(19,20)$. However, murine models presented conflicting results, as IL-17-KO donor $\mathrm{T}$ cells either reduced (21) or exacerbated aGvHD (22). Similarly, human aGvHD studies reported discordant results. Indeed, blood/tissue Th17 cells were found to be either increased (23) or decreased (24, 25). Interestingly, some studies provided data suggesting Th17 involvement in the transition from aGvHD to $\mathrm{G}$ vHD. Indeed, Chen et al. reported the expansion of Th17 in the early phase of aGvHD playing a role in the development of later autoimmune-like disease (26) and, in parallel, Carlson et al. described the role of Th17 in severe skin and lung injuries that resemble cGvHD (27).

With respect to the pathogenesis of $\mathrm{cGvHD}$, the role of Th17 cells is less controversial. Studies have demonstrated a role for Th17 cells in murine models with features of autoimmunity (26), scleroderma (28), and multiorgan system disease with bronchiolitis obliterans (BO) in a CSF-1/CSF-1R-(29) and STAT3-dependent manner $(30,31)$. In humans, there is a paucity of data. Dander et al. showed an increase of Th17 cells in the blood of patients with active CGvHD (23), and a mixed Th1/Th17 signature was observed in the skin of patients with active disease (32). More recently, we identified candidate biomarkers (CCL14 and CD146) in the plasma of patients developing gastrointestinal (GI) GvHD that revealed an activated Th17prone $\mathrm{T}$ cell population $\left(\mathrm{CD} 4^{+} \mathrm{CD} 146^{+} \mathrm{CCR} 5^{+} \mathrm{T}\right.$ cells) participating in the pathogenesis of aGvHD (33). Interestingly, CD146 appeared associated with cGvHD in our recent large-scale proteomic study (7). Altogether, these data suggest studying the role of Th17cells and the ROR $\gamma t$ pathway during cGvHD pathogenesis, and targeting this subset may provide a clinical benefit.

Strategies specifically targeting the Th17 subset have included antibody-mediated neutralization of IL-17 or IL-23 and were predominantly evaluated in the field of autoimmune diseases (34-36). The Th17 program is dependent on the master regulator ROR $\gamma$ t and STAT3 signaling. Dual ROR $\gamma$ t or STAT3 pathway inhibitors have been developed, such as the small GTPase, $\rho$-associated coiled-coil containing protein kinase 2 (Rock2) inhibitor, KD025. We recently showed that KD025 was efficient in suppressing murine and human cGvHD through inhibition of ROR $\gamma$ t and STAT3, leading to reduced IL-17 and IL-21 cytokine production and $\mathrm{T}$ follicular helper (TFH) cells that can support pathogenic antibody production during cGvHD (31, 37). Via its effects on STAT5, Treg production also is facilitated $(31,38)$. Other inhibitors can provide a more specific approach by targeting the Th17 program (e.g., ROR $\gamma \mathrm{t}$ ), only without affecting all downstream STAT3 signaling (e.g., TFH and Th17), in order to preserve other immune functions such as humoral immunity (STAT3/4-dependent) $(39,40)$. One such small-molecule ROR $\gamma$ t inhibitor is TMP778, 
which acts through several modalities: interruption of ROR $\gamma \mathrm{t}$ binding its target genes, disrupting ROR $\gamma \mathrm{t}$ interaction with other transcription factors or coactivators, and promotion of Gata3 transactivation (40). Previous reports demonstrated the role of TMP778 interfering with Th17 cell differentiation and its activity during mouse models of autoimmune diseases $(40,41)$. Molecular studies showing a STAT3-dependent mechanism of action suggest ROR $\gamma$ t inhibitor use as a candidate treatment of cGvHD.

Here, we show that CD146-expressing cells are increased in the context of cGvHD in both human and mice, and they harbor a Th17 polarization with upregulation of ROR $\gamma \mathrm{t}$ and increased capacity to secrete IL-17. This population was required for cGvHD pathogenesis, as CD146 KO, anti-IL-17 neutralizing antibody, and ROR $\gamma$ t-specific inhibition (TMP778) each alleviated disease severity. Altogether, our data support that ROR $\gamma$ t inhibitors could be used as a new therapeutic option for cGvHD.

\section{Results}

Increased frequencies of $C D 146^{+}$and $C D 146^{+} C C R 5^{+} C D 4 T$ cell subsets during $c G v H D$. CD146 and CCR5 represent 2 molecules facilitating migration of $\mathrm{T}$ cells through the endothelium in response to homing signals released from inflamed tissues $(42,43)$. We previously demonstrated that patients with GI GvHD presented an increased frequency of $\mathrm{CD} 146^{+} \mathrm{CCR} 5^{+} \mathrm{T}$ cells compared with patients without GvHD or nonenteritis GvHD, or with isolated skin GvHD (33). These observations suggest a role for the involvement of this population in late aGvHD manifestations. To evaluate the role of CD146- and CCR5-expressing cells in the pathogenesis of human $\mathrm{cGvHD}$, we performed multiparameter flow cytometry on peripheral blood samples from 40 HSCT patients with and without active cGvHD ( $n=20$ patients/group) at the time of sample collection. Patient clinical characteristics are listed in Table 1.

First, we analyzed the expression of CD146 within CD4 conventional T cells (Tcon), defined as nonTregs (i.e., excluding $\mathrm{CD} 25^{\text {hi }} \mathrm{CD} 127^{\text {low }}$ cells). CD146 was significantly upregulated in CD4 Tcon during cGvHD compared with patients without $\mathrm{cGvHD}$ (median percentage: 6.76 during active cGvHD vs. 3.28 without cGvHD, $P<1 \times 10^{-4}$ ) (Figure $1, \mathrm{~A}$ and $\mathrm{B}$ ). Interestingly, CD146 ${ }^{+}$Tcon appeared to be positively associated with cGvHD disease severity, according to NIH criteria (Figure 1B). We also analyzed the subset coexpressing CD146 and CCR5 $\left(\mathrm{CD} 146^{+} \mathrm{CCR} 5^{+}\right)$. Although representing a smaller fraction within $\mathrm{CD} 4^{+} \mathrm{T}$ cells, $\mathrm{CD}_{146}{ }^{+} \mathrm{CCR} 5^{+}$within the Tcon subset was significantly increased during active cGvHD (median percentage: 0.62 during active $c G v H D$ vs. 0.27 without $\mathrm{cGvHD}, P=0.015$ ) (Figure $1 \mathrm{C}$ ), similar to the $\mathrm{CD} 146^{+}$fraction. We also examined $\mathrm{CD}^{+}$Treg (defined as $\mathrm{CD} 25^{\text {hiF }}{ }^{2} \mathrm{xP}^{+}$) and found, similarly to aGvHD (33), a significant upregulation of CD146 (median percentage: 21.65 during active $\mathrm{GGvHD}$ vs. 13.2 without $\mathrm{cGvHD}, P=1 \times$ $10^{-4}$ ) (Figure 1D) and an increased frequency of the double-positive subset $\left(\mathrm{CD} 146^{+} \mathrm{CCR} 5^{+}\right)$within the Treg subset (median percentage: 3.4 during active $\mathrm{cGvHD}$ vs. 2.1 without $\mathrm{cGvHD}, P=0.007$ ) (Figure $1 \mathrm{E}$ ) during cGvHD. We observed similar findings when looking at absolute counts (Supplemental Figure 1, A-D; supplemental material available online with this article; https://doi.org/10.1172/jci.insight.92111DS1). As we previously showed the increase of CD146-expressing subsets in a cohort of aGvHD, we analyzed our active cGvHD cohort, in which half had previously developed aGvHD. This analysis did not reveal any impact of prior aGvHD development (Supplemental Figure 1, E-J). Taken together, these data indicate that both $\mathrm{CD}_{146^{+}}$and $\mathrm{CD} 146^{+} \mathrm{CCR} 5^{+} \mathrm{T}$ cell subsets with increased migration capacity are increased during $\mathrm{CGvHD}$.

CD146-expressing $C D 4^{+} T$ cells are skewed toward a Th17 profile during cGvHD. We next evaluated whether $\mathrm{CD}_{146^{+}}$Tcons that were increased in patients with $\mathrm{cGvHD}$ expressed a specific polarization profile. Previous reports suggested that $\mathrm{CD} 146^{+}$subsets tended to be polarized toward a Th17 phenotype and function (44). As ROR $\gamma$ t is a major transcription factor contributing to the Th17 polarization of a $\mathrm{T}$ cell subset, we assessed its expression level by flow cytometric quantification of mean fluorescent intensity (MFI) in healthy donor (HD) samples (Supplemental Figure 2, A-C) and confirmed the upregulation of ROR $\gamma \mathrm{t}$ in CD146+ CD4 (Supplemental Figure 2A) and CCR5 ${ }^{+}$CD4 (Supplemental Figure 2, B and C) Tcon, as well as Treg subsets, in addition to the $\mathrm{CD} 146^{+} \mathrm{CCR} 5^{+} \mathrm{CD} 4$ Tcon subset (Supplemental Figure 2, B and C). We then evaluated the relative ROR $\gamma$ t expression levels among HSCT patients with or without active CGvHD. In our cohort, ROR $\gamma t$ expression was increased in active cGvHD patients compared with no cGvHD when examining effector $\mathrm{CD}^{+}{ }^{+} \mathrm{T}$ cells $\left(\mathrm{CD} 4^{+}\right.$Tcon, median ROR $\gamma \mathrm{t}$ MFI: 244 vs. 197 , respectively, $\left.P=0.0045\right)$ (Figure 2, A and B), as well as in both the CD146+ CD4 Tcon (median MFI: 291.5 vs. 244.5, respectively, $P=0.029$ ) (Figure $2 \mathrm{C}$ ) and CD $146{ }^{+} \mathrm{CCR}^{+} \mathrm{CD} 4$ Tcon (median MFI: 356 vs. 269.5 , respectively, $P=0.042$ ) subsets (Figure 2D). The same trends were observed for the CD4+ Treg (median ROR $\gamma \mathrm{t}$ MFI: 192 vs. 156.5 for active $\mathrm{cGvHD}$ and no $\mathrm{cGvHD}$, respectively, $P=0.0066$ ) (Figure $2 \mathrm{E}$ ), as well as in $\mathrm{CD} 146^{+} \mathrm{CD} 4$ Treg 
Table 1. Clinical characteristics of HSCT patients

\begin{tabular}{|c|c|c|c|}
\hline & & $\begin{array}{c}\text { Active cGvHD } \\
\qquad n=20\end{array}$ & $\begin{array}{c}\text { No cGvHD } \\
n=\mathbf{2 0}\end{array}$ \\
\hline Age & Median (range) & $\begin{array}{c}59 \\
(25.9-75.6)\end{array}$ & $\begin{array}{c}60.4 \\
(32.6-74.9)\end{array}$ \\
\hline Sex ratio & $M / F$ & 1.85 & 1 \\
\hline \multirow[t]{2}{*}{ Conditioning regimen } & MAC & 6 & 9 \\
\hline & RIC & 14 & 11 \\
\hline \multirow[t]{2}{*}{ Graft Source } & $B M$ & 1 & 5 \\
\hline & PBSC & 19 & 15 \\
\hline \multirow[t]{3}{*}{ Donor } & $M R D$ & 6 & 8 \\
\hline & MUD & 11 & 10 \\
\hline & $m m U D$ & 3 & 2 \\
\hline Time from SCT (months) & Median (range) & $\begin{array}{c}31.4 \\
(11.5-123.8)\end{array}$ & $\begin{array}{c}37.7 \\
(12-140.9)\end{array}$ \\
\hline aGvHD (\%) & Grade $2-4$ & $10(50)$ & $3(15)$ \\
\hline \multirow[t]{3}{*}{ cGvHD NIH grade (\%) } & Mild & $8(40)$ & N/A \\
\hline & Moderate & $8(40)$ & $\mathrm{N} / \mathrm{A}$ \\
\hline & Severe & $4(20)$ & $\mathrm{N} / \mathrm{A}$ \\
\hline IST at the time of sample & Yes (\%) & $14(70)$ & $1(5)$ \\
\hline Steroid at the time of sample & Yes (\%) & $8(40)$ & 0 \\
\hline Mean steroid dose & $\mathrm{mg} / \mathrm{kg} /$ day & 0.18 & N/A \\
\hline
\end{tabular}

$M$, male; F, female; MAC, myeloablative conditioning; RIC, reduced intensity conditioning; MRD, matched related donor; MUD, matched unrelated donor; mmUD, mismatched unrelated donor; PBSC, peripheral bood stem cell; SCT, stem cell transplantation; aGvHD, acute GVHD; cGvHD, chronic GVHD; IST, immunosuppressive therapy.

(median MFI: 200 vs. 160.5, respectively, $P=0.0056$ ) (Figure $2 \mathrm{~F}$ ), and CD146 ${ }^{+} \mathrm{CCR} 5^{+} \mathrm{CD} 4$ Treg (median MFI: 210.5 vs. 162 , respectively, $P=0.0007$ ) (Figure $2 \mathrm{G}$ ) subsets. Since ROR $\gamma$ t upregulation in Tregs may have affected Treg function, we assessed suppressor function according to CD146 expression levels in an in vitro suppression assay with Tcon. We observed a significantly decreased suppressive capacity of $\mathrm{CD}_{146^{+}}$Treg compared with CD146- Treg (Figure 2H). Taken together, these data suggest that CD146and CD146/CCR5-expressing cells, in both Tcon and Treg, are polarized toward a Th17 phenotype, which is augmented during $\mathrm{CGvHD}$ and may contribute to its pathogenesis.

$C D 146^{+} C C R 5^{+} C D 4 T$ cell subsets harbor a mixed polarization. Because the chemokine receptor CCR5 is associated with Th1 polarization (45), we also evaluated T-bet expression, a canonical transcription factor of Th1 subset, within our population of interest. In HDs, CCR5 expression within Tcon had a greater impact on T-bet upregulation compared with CD146 (T-bet mean MFI: 661.5 in CD146-CCR5 ${ }^{+}$vs. 446.3 in CD146-CCR5 ${ }^{-}, P=0.0078 ; 661.5$ in CD146-CCR5 ${ }^{+}$vs. 520.9 in $\mathrm{CD}^{-} 146^{+} \mathrm{CCR}^{-}, P=0.07$ ) (Supplemental Figure 2, D-F). We then evaluated IFN- $\gamma$ production as a key Th1 signature cytokine. Consistent with T-bet upregulation data, the CD146-CCR5 $5^{+}$-expressing subset produced a greater amount of IFN- $\gamma$ compared with the reciprocal $\mathrm{CD} 146^{+} \mathrm{CCR} 5^{-}$subset (mean IFN- $\gamma$ production: 66.15 vs. 23.69 , respectively, $P=0.002$ ) (Supplemental Figure $3, \mathrm{~A}-\mathrm{C}$ ). Together, our data showed in HD that CD $146^{+} \mathrm{CCR} 5^{+}$-expressing $\mathrm{CD}^{+}{ }^{+} \mathrm{T}$ cells present both features of Th1 (T-bet/IFN- $\gamma$ ) and Th17 (ROR $\left.\gamma \mathrm{t} / \mathrm{IL}-17\right)$, with CD146 driving most of the Th17 phenotype (Supplemental Figure 2, B and C, and Supplemental Figure 3, $\mathrm{D}-\mathrm{F}$ ). As $\mathrm{CD} 146^{+}$and $\mathrm{CD} 146^{+} \mathrm{CCR} 5^{+} \mathrm{CD} 4 \mathrm{~T}$ cells are highly correlated (Spearman's $\mathrm{r}=0.81, P=0.016$, in HD), we evaluated whether $\mathrm{CD} 146^{+}$-expressing $\mathrm{CD} 4^{+} \mathrm{T}$ cells were enriched for a Th1/Th17 subset previously described as pathogenic. When we analyzed CD146 ${ }^{+} \mathrm{CD} 4 \mathrm{~T}$ cells, we observed a significant enrichment of a population secreting both cytokines IFN- $\gamma^{+} \mathrm{IL}-17^{+}$(mean percentage: $2.36 \%$ for CD $146^{+}$ subset vs. $0.179 \%$ for $\mathrm{CD} 146^{-}, P=0.002$; and $4.579 \%$ for $\mathrm{CD} 146^{+} \mathrm{CCR}^{+}$vs. $0.236 \%$ for $\mathrm{CD}^{+}$excluding the $\mathrm{CD} 146^{+} \mathrm{CCR} 5^{+}$subset, $\mathrm{P}=0.002$ ) (Supplemental Figure 3, G-I). Interestingly, in our cohort, the Th1/Th17 (IFN- $\left.\gamma^{+} \mathrm{IL}-17^{+}\right)$subset within $\mathrm{CD} 146^{+} \mathrm{CD} 4 \mathrm{~T}$ cells appeared to be associated with active cGvHD disease severity (Supplemental Figure 4) (median percentage of IFN- $\gamma^{+} \mathrm{IL}-17^{+} \mathrm{CD} 146^{+}$in CD $4^{+}$ T cells: $0.0152 \%$ for mild vs. $0.0438 \%$ for moderate, $P=0.064 ; 0.0438 \%$ for moderate vs. $0.075 \%$ for severe, $P=0.367 ; P=0.048$ between mild and severe). 
A

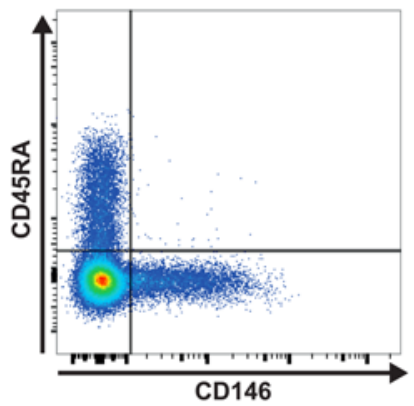

Active cGVHD
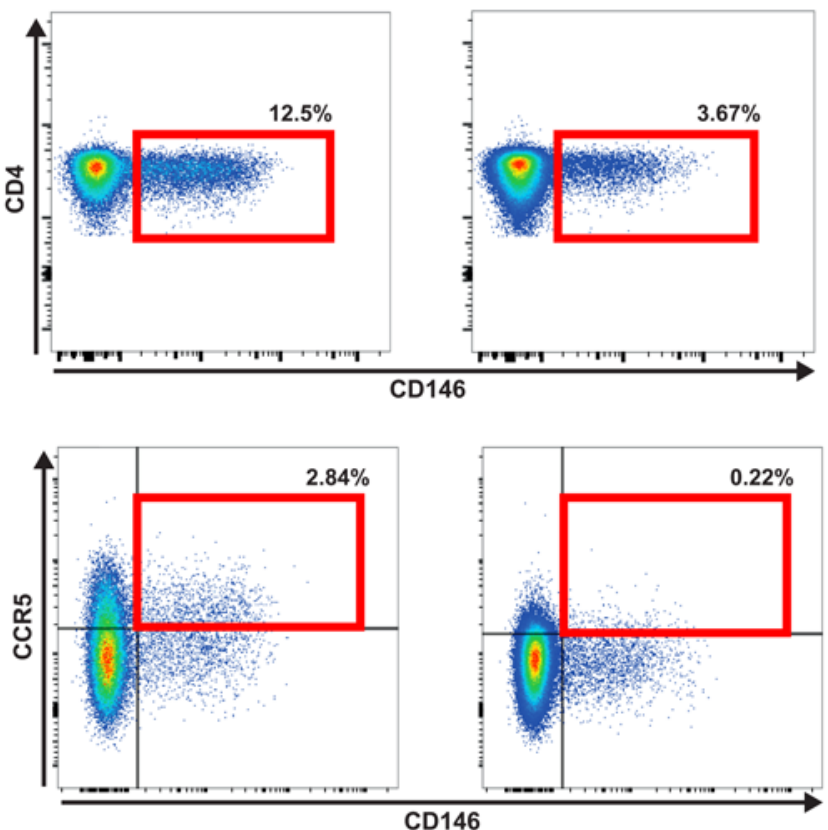

D

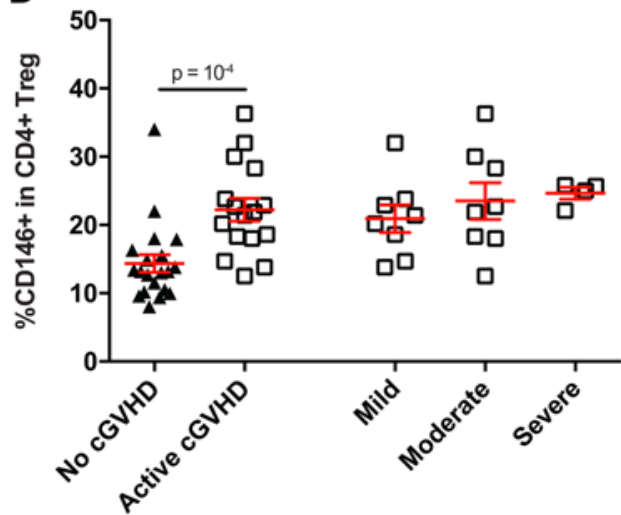

B

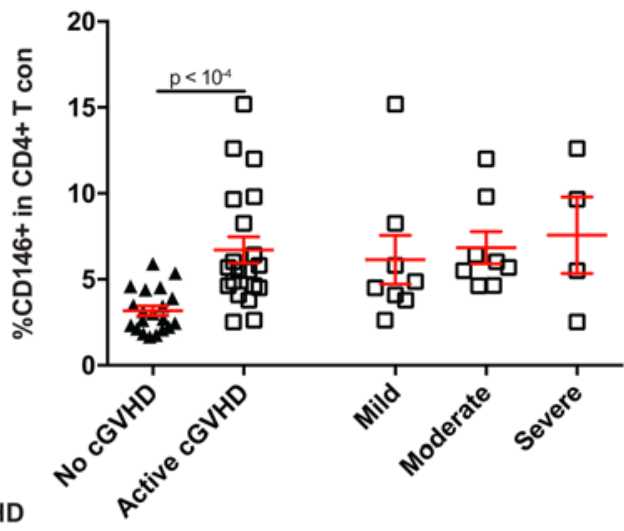

C
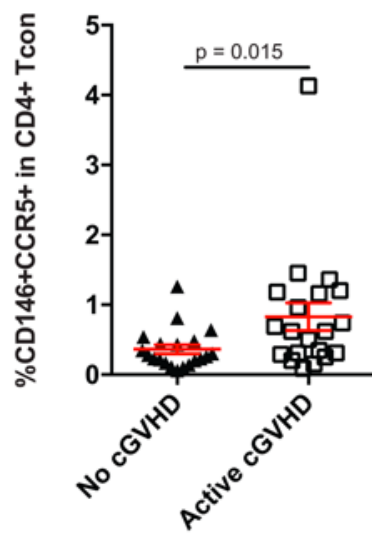

Figure 1. CD146 and CCR5 expression within CD4 ${ }^{+}$Tcon (non CD25 ${ }^{\text {hiCD127low }}$ within CD4 ${ }^{+} \mathrm{T}$ cells) and Treg (CD25 ${ }^{\text {hiFoxP3 }}{ }^{+}$ within $\mathrm{CD4}^{+} \mathbf{T}$ cells) subsets. (A) Color plots representing the gating strategy of CD146-expressing cells according to CD45RA, and representative examples of $C D 146^{+}$and $C D 146^{+} C C R 5^{+}$subsets (in CD4+ $4^{+}$live lymphocyte gate) in 1 active cGvHD patient and 1 patient without cGvHD. (B-E) Data shown are dot plots (mean \pm SEM) according to different clinical groups: No $(n=20)$ or active cGvHD $(n=20)$ and different clinical grades of cGvHD according to NIH criteria (mild, $n=$ 8 ; moderate, $n=8$; severe, $n=4$ ). Unpaired $t$ test comparing the frequencies between groups. Comparisons in $\mathbf{B}-\mathbf{E}$ were analyzed using the Wilcoxon rank-sum test. 
A

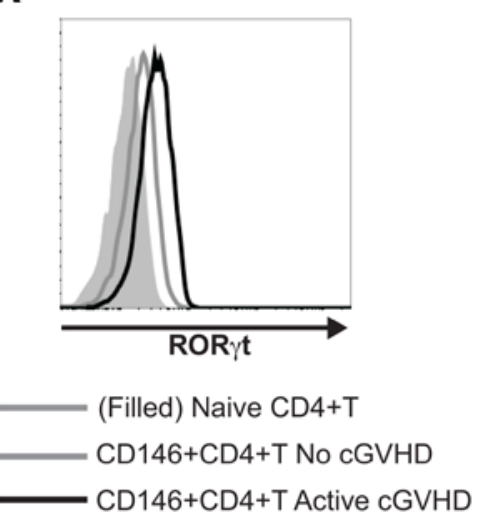

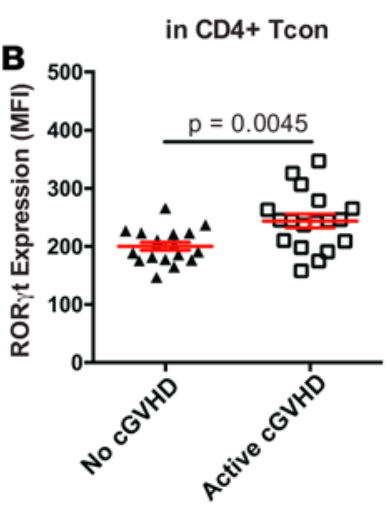
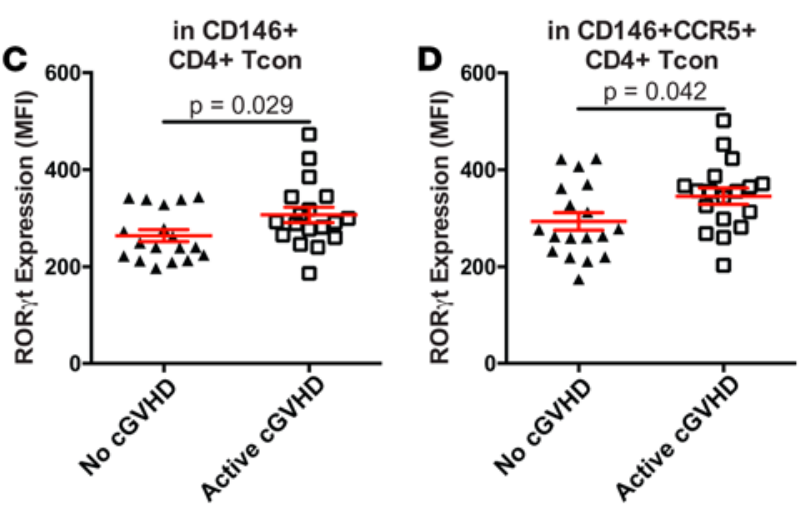
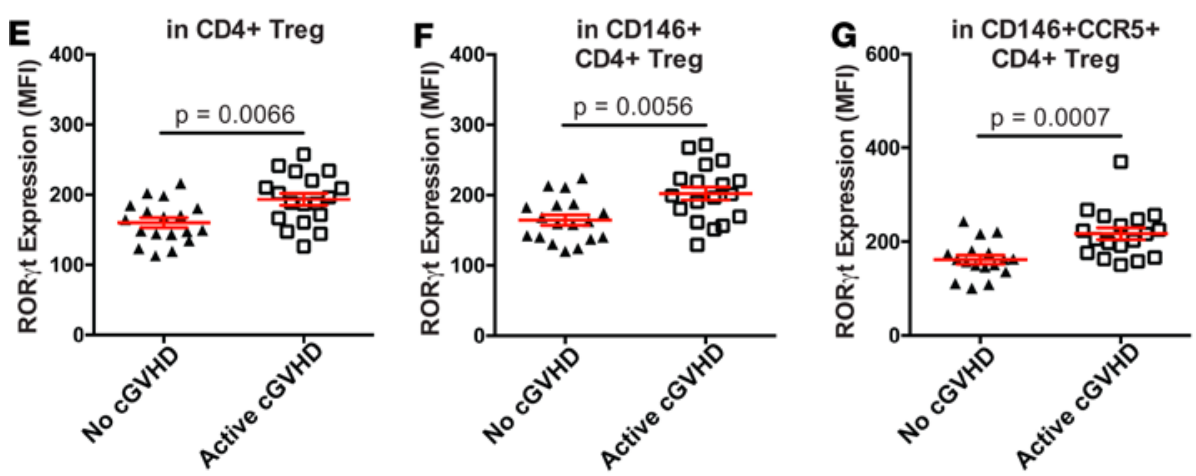

H
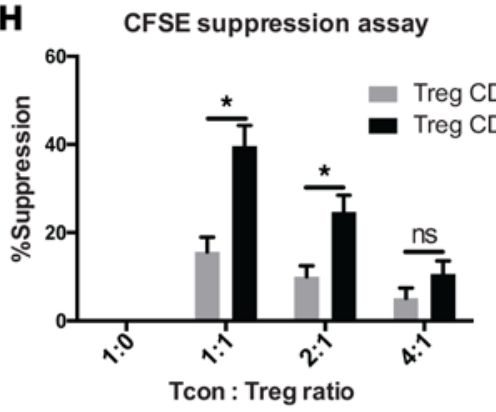

Figure 2. Analysis of Th17-related transcription factor according to CD146 and CCR5 expression. (A) Single parameter histogram representing ROR $\gamma \mathrm{t}$ expression and comparing the level of expression in naive CD4+ T cells (CD45RA ${ }^{+}$) with the 1 in CD146+ CD4 T cells in 1 active-cGvHD and 1 no-cGvHD representative patients. (B-C) ROR $\gamma$ t intracellular staining in CD146 ${ }^{+}$and CD146+CCR5 ${ }^{+}$subsets (Tcon and Treg) revealed a skewed polarization toward a Th17 profile in cGvHD patients. Data shown are dot plots (mean \pm SEM) according to different clinical groups: No $(n=18)$ or active cGvHD ( $n=18)$. Unpaired $t$ test comparing ROR $\gamma t$ MFI between groups. (H) Comparison of Treg suppressive capacity according to CD146 expression. Treg were sorted according to the expression of CD146 and cocultured with CFSE-labeled Tcon for 5 days at different ratios upon stimulation with coated $\alpha$ CD3 and soluble $\alpha$ CD28. Bar graph representing mean \pm SEM values after 6 experiments. ${ }^{*} P<0.05$, paired $t$ test. Comparisons in B-G were analyzed using the Wilcoxon rank-sum test. Comparisons in $\mathbf{H}$ were analyzed using the Wilcoxon signed-rank test.

CD146 deficiency of donor T cells alleviates mouse $G$ GHD model that includes BO. Here, our data from human samples suggest a role for the $\mathrm{CD} 146^{+}$subset in the pathogenesis of $\mathrm{cGvHD}$. Thus, we hypothesized that HSCT with CD146-KO donor T cells would preclude cGvHD generation using a well-established multiorgan cGvHD mouse model system that has $\mathrm{BO}$ as a prominent clinicopathological manifestation. We previously showed that B10.BR $\left(\mathrm{H} 2^{\mathrm{k}}\right)$ recipients receiving BM and splenocytes from C57BL/6 (B6) donors developed a systemic multiorgan system cGvHD with BO mimicking human cGvHD (shown by pulmonary functional tests and lung fibrosis), representing a powerful tool to evaluate therapeutic interventions to better understand cGvHD pathogenesis and assess pharmacological interventions (12, 31, 46, 47). In this model, donor T cells mediate cGvHD via a RORyt-, STAT3-, and IL-17/IL-21-dependent mechanism $(28,31)$. In addition, pulmonary fibrosis was shown to depend upon Th17 (48) and donor macrophages in the context of cGvHD-related BO (29). When using splenocytes from CD146-KO vs. WT donors (together with WT BM), pulmonary functional tests (resistance, compliance, elastance) performed 2 months after transplant were each significantly improved and comparable with BM-only mice that did not develop cGvHD (Figure 3A). There was a statistical trend toward decreased lung histopathology (Figure 3B), while histopathology in other target organs (liver and colon) was not decreased (data not shown) in the CD146-KO group as compared with the WT group. Similarly, organ fibrosis assessed by trichrome staining of lung cryosections demonstrated markedly decreased collagen deposition with CD146-KO donors compared with WT (Figure 3C) and was quantitatively confirmed using a hydroxyproline assay to measure collagen burden (Figure 3D), whereas, consistent with histopathological analysis, no significant differences were seen in liver and colon fibrosis (data not shown). Flow cytometry of single-cell suspensions was performed to quantify the frequency of pathogenic $\mathrm{T}$ 
A

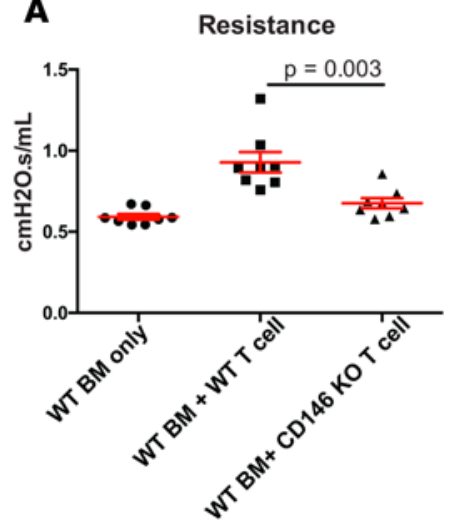

B Lung Histopathology

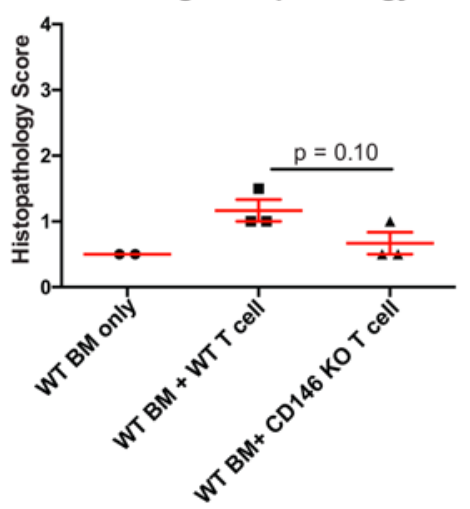

Elastance

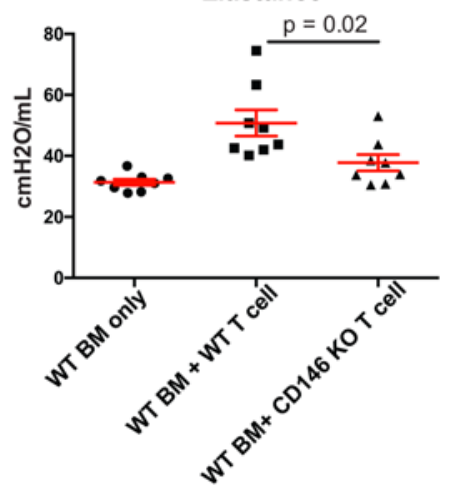

C

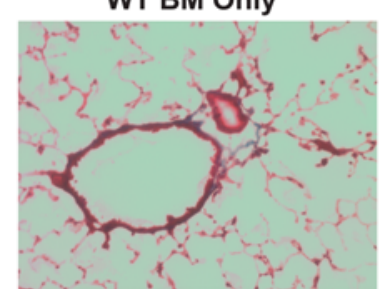

WT BM + WT T cell

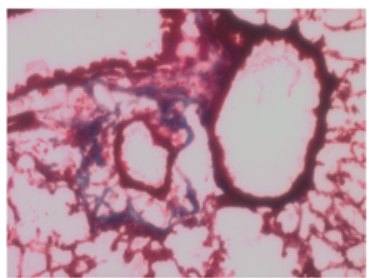

WT BM + CD146 KO T cell

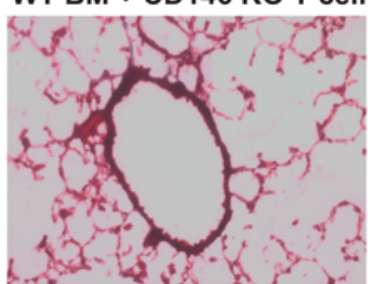

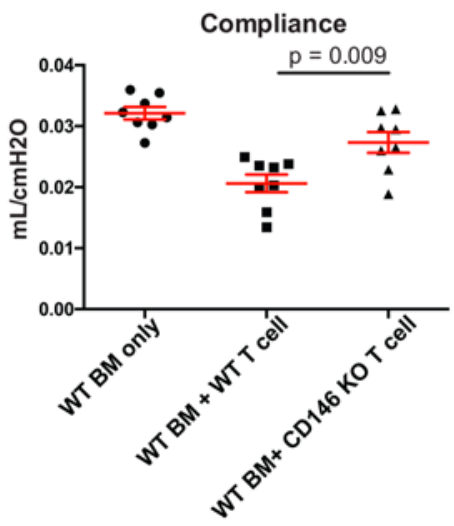

D Lung Hydroxyproline

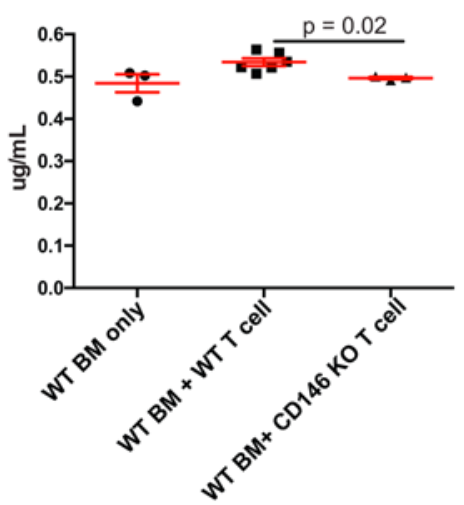

Figure 3. CD146-expressing T cells are necessary for the development of CGvHD and lung fibrosis in a bronchiolitis obliterans model. B10.BR mice were transplanted with WT B6 BM without or with WT B6 T cells or B6 CD146-KO T cells as mentioned. (A) Mice were evaluated at day 60 for pulmonary function, measurement at day 56 after HCT, $n=8$ per group. (B) Histopathology score of the lung at day 56 after HCT, $n=3$ per group. (C) Lung sections were stained with trichrome for collagen deposition, 20x magnification. Representative data from 3 experiments. (D) Hydroxyproline quantitative measure in the lung of euthanized mice, $n=3-6$ mice per group. Comparisons in $\mathbf{A}, \mathbf{B}$, and $\mathbf{D}$ were analyzed using the Wilcoxon rank-sum test.

cell subsets with Th17-related features within the lung. Similar to patient data, mice developing cGvHD had a significant increase in the IFN- $\gamma^{+} \mathrm{IL}-17^{+}$subset within both $\mathrm{CD} 146^{+}$and $\mathrm{CD} 146^{+} \mathrm{CCR} 5^{+}$fractions, which was abrogated when using splenocytes from CD146-KO donors (Figure 4A). As we previously showed the involvement of macrophages in the lung fibrosis (29), we undertook the quantification of CD68 expression on lung cryosection and observed a marked increase in macrophage number during cGvHD that was alleviated in mice receiving CD146-KO splenocytes (Figure 4B). We also previously showed that development of BO during murine $\mathrm{CGvHD}$ was associated with increased $\mathrm{T}$ foll cells along with germinal center B cells (GC B cells) within the spleen (47). Splenic flow cytometry indicated no difference in TFH or GC B cells between the mice receiving CD146-KO vs. WT T cells (Figure 4C). Taken together, our data indicate that CD146 expression on donor T cells is necessary for cGvHD BO development and infiltration of pathogenic IFN- $\gamma^{+} \mathrm{IL}-17^{+}$ subset and macrophages in the lung, rather than via direct effects on splenic TFH/GC B cell interactions. 
A

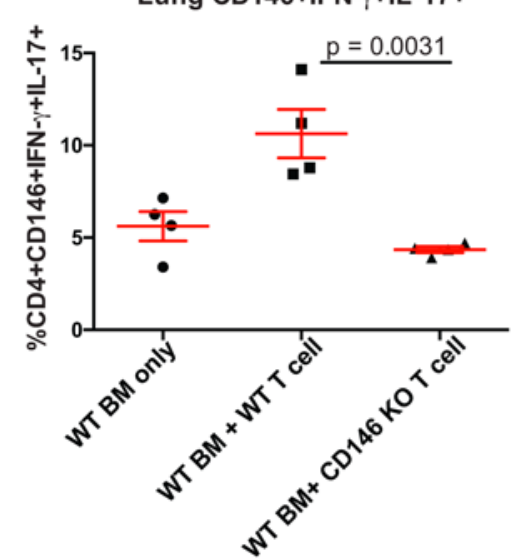

Lung CD146+CCR5+IFN- $\gamma+$ IL-17+
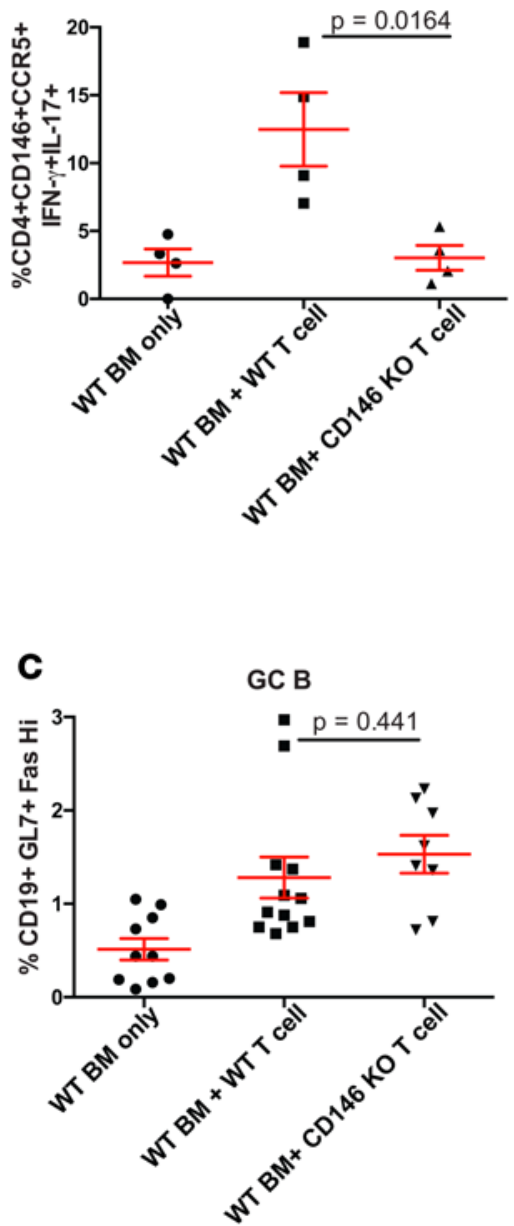

B
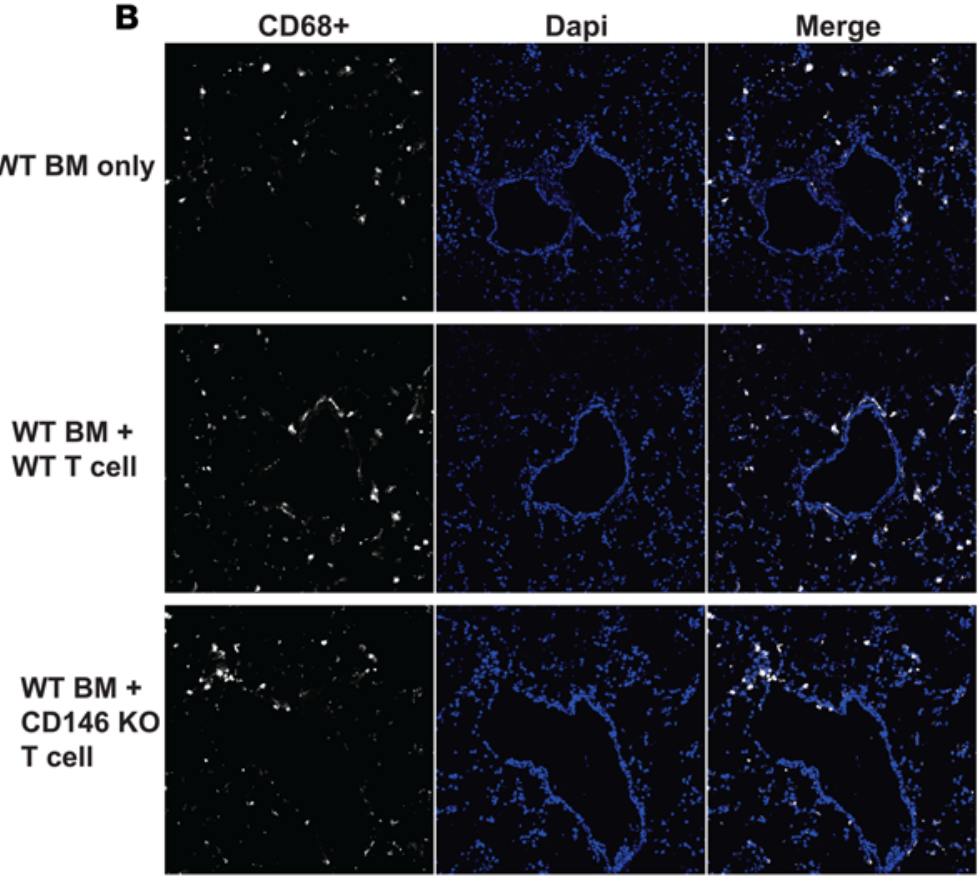

Macrophage infiltration

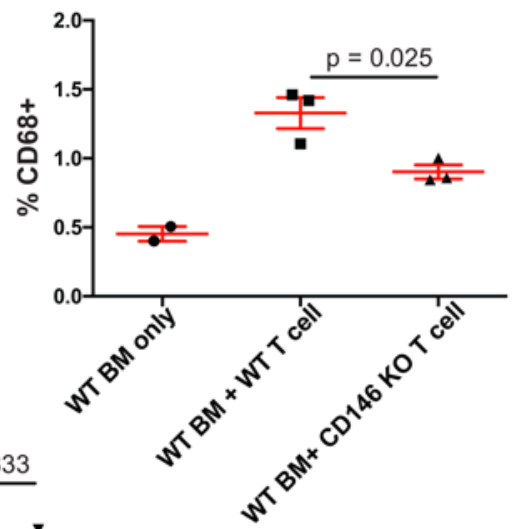

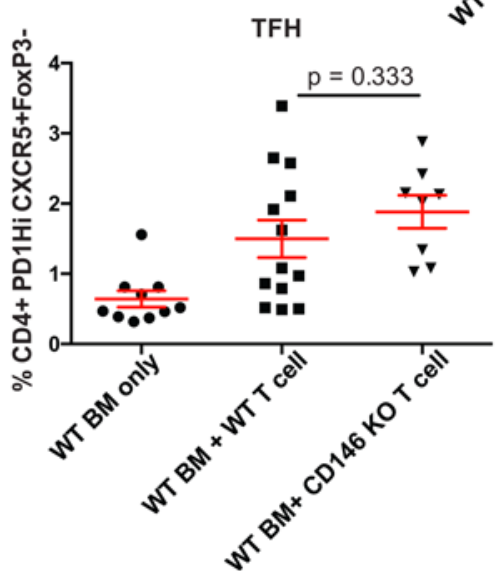

Figure 4. CD146 deficiency of donor T cells is associated with decreased pathogenic IFN- $\gamma^{+}$IL-17+ $T$ cells and macrophage infiltration, but an intact TFH-GC B cell axis. (A) Flow cytometry was performed on single-cell suspension from lungs of different animal groups analyzed by flow cytometry at day 56, after stimulation with PMA-ionomycin in the presence of protein transport inhibitor. Data represent frequencies (mean \pm SEM) of IFN$\gamma^{+} \mathrm{IL}-17^{+}$subset within CD146+ (left panel) or CD146+CCR5 $5^{+}$fractions (right panel). (B) Lung cryosection were stained for CD68 expression (macrophages) together with DAPI to quantify cellular infiltrate. A representative example of immunofluorescence staining is shown of animals receiving BM only, BM + WT splenocytes (cGVHD), or BM + CD146-KO splenocytes (20x magnification). Automated quantification of macrophages relative to cellular infiltrate was performed to ensure reproducible analysis and is summarized in terms of frequencies (mean \pm SEM). $n=3$ mice per group, BM only $n=2$. (C) CD146-KO does not impact T-B cross talk within lymphoid organ. GC B cells (CD19+CL7+Fas $\left.{ }^{\text {hi }}\right)$ and TFH (CD4+CXCR5+PD1 $\left.1^{\text {hiFoxP3 }} 3^{-}\right)$were analyzed by flow cytometry after spleen digestion at day 56 after transplant in animals receiving BM only, BM + WT splenocytes, or BM + CD146-KO splenocytes. $n=3-7$ mice per group. Comparisons in $\mathbf{A}-\mathbf{C}$ were analyzed using the Wilcoxon rank-sum test 
We and others have previously described the role of CD146 and ICOS stimulation in the development of human pathogenic IFN- $\gamma^{+} \mathrm{IL}-17^{+} \mathrm{T}$ cells $(33,49)$. Therefore, we sought to confirm the role of both CD146 and ICOS in murine IFN- $\gamma^{+} \mathrm{IL}-17^{+} \mathrm{T}$ cells by differentiating naive CD146-KO vs. CD146 WT T cells with either CD3/CD28 stimulation or CD3/ICOS stimulation. We showed that Th17 differentiation conditioning and ICOS stimulation significantly increased the number of cells coexpressing IL-17/IFN- $\gamma$ and ROR $\gamma \mathrm{t} / \mathrm{IL}-21$ in cultures derived from naive CD146 WT T cells as compared with cultures derived from naive CD146-KO T cells (Supplemental Figure 5). These data suggest a crucial role of CD146 in the development of IFN- $\gamma^{+} \mathrm{IL}-17^{+} \mathrm{T}$ cells and BO model that point to an effect on the Th17-related homing capacity of pulmonary macrophages, similar to the Th17-dependent BO observed in lung transplant (48).

TMP778 targeting of ROR $\gamma$ t suppresses the development of pathogenic Th1/Th17 and CD146 ${ }^{+} C C R 5^{+}$CD4 T cells in vitro. We have now shown that $\mathrm{CD} 146^{+} \mathrm{CCR} 5^{+} \mathrm{CD} 4 \mathrm{~T}$ cells are Th17 committed, express higher levels of Th17 markers, and exhibit a pathogenic Th1/Th17 phenotype (coexpressing IL-17 and IFN- $\gamma$ ) (15). Toward clinical translation, we sought to determine whether potentially pathogenic Th1/Th17 cell differentiation could be blocked in vitro. Therefore, we measured the effect of TMP778, an inhibitor of the Th17 master transcription factor ROR $\gamma \mathrm{t}$, on in vitro human Th1/Th17-polarized cells and CD146 ${ }^{+}$CCR $5^{+}$ CD4 T cells. Total CD4 T cells from HD were cultured under Th17 polarizing condition in the presence of increasing doses of TMP778 or vehicle control DMSO. TMP778 significantly reduced the frequency of IFN- $\gamma^{+} \mathrm{IL}-17^{+} \mathrm{T}$ cells in a dose-dependent manner (Figure 5A). In addition, the frequency of CD $146^{+} \mathrm{C}-$ $\mathrm{CR}^{+} \mathrm{T}$ cells was also inhibited in a dose-dependent manner (Figure 5B). Similarly, TMP778 at a concentration of $0.1 \mu \mathrm{M}$ and $1 \mu \mathrm{M}$ significantly inhibited the generation of Th1/Th17 and CD146 ${ }^{+} \mathrm{CCR} 5^{+}$CD4 $\mathrm{T}$ cells in allogeneic mixed lymphocyte reaction (MLR) cultures (Supplemental Figure 6). Together, our results indicate that TMP778 can suppress not only the differentiation of Th17, but also the development of Th1/Th17 and CD146+CCR5 ${ }^{+}$CD4 T cells in vitro.

Pharmacological and neutralizing antibody inhibition of ROR $\gamma t$, STAT3, or IL-17 reverses established mouse $c G v H D$. Results above suggested a relationship between CD146 and Th17 polarity. Thus, we evaluated the in vivo cGvHD effect of pharmacological inhibition of ROR $\gamma \mathrm{t}$ with a small-molecule inhibitor that showed strong efficiency in other Th17-driven disease (40) and under the in vitro Th17 polarizing conditions from HD described immediately above. TMP778 interacts with ROR $\gamma \mathrm{t}$ to hamper its transcription factor activity and, consequently, IL-17 secretion $(40,41)$. Toward clinical translation, we treated recipients with TMP778 beginning on day $28(\mathrm{~d} 28)$ at the time of established cGvHD. TMP778 treated mice showed a significant improvement of pulmonary function tests at $\mathrm{d} 60$, reaching the level of recipients receiving CD146-KO splenocytes or BM only (Figure 6). Similarly, administration of an anti-IL-17 blocking antibody on d28 significantly improved each of the pulmonary function test parameters, alleviating BO-related cGvHD (Figure 6).

\section{Discussion}

In the present study, we sought to identify and characterize a new $\mathrm{T}$ cell subset involved in human and murine cGvHD. Defining cellular biomarkers of cGvHD, such as $\mathrm{T}$ cell subsets, remains a major goal in order to improve our understanding and to develop targeted therapies. Here, we define a pathogenic CD4 T cell population based on the expression of CD146 and CCR5 reflecting its capacity to migrate to inflamed tissue and to interact with endothelial barriers in the context of alloreactivity.

CD146 (also called melanoma cell adhesion molecule [MCAM]) is a cell adhesion glycoprotein expressed on lymphoid cells, endothelial cells, smooth muscle cells, and tumor cells, and displays homophilic or heterophilic interaction (50). It has been shown to play a major role in $\mathrm{T}$ cell migration through interaction with endothelial cells $(33,43)$. Hence, CD146 expression on T cells has been shown as a surrogate of subsets with transendothelial migration capacity (33) during the course of inflammation. Our study revealed that patients with active cGvHD had significantly higher CD146 expression in CD4 T cells, including both Tcon and Treg subsets.

CD146 can be upregulated on T cells upon TCR or mitogen stimulation, reflecting $\mathrm{T}$ cell activation. When binding CD146 through homophilic interaction, downstream transducing signals induce phosphorylation of cellular proteins such as Pyk2, focal adhesion kinase, and paxillin, thus promoting transendothelial migration (43). Similarly, we also evaluated another subset of CD146-expressing cells, the CD146/CCR5 double-positive CD4 T cells, which were increased in patients with cGvHD. These CD146-expressing CD4 T cells (including CD $146^{+}$CCR $5^{+}$) exhibited Th17 features. Specifically, CD146 ${ }^{+} \mathrm{CD} 4 \mathrm{~T}$ cells express a significantly higher concentration of ROR $\gamma \mathrm{t}$ and IL-17 intracellular expression upon stimulation. Previous reports 

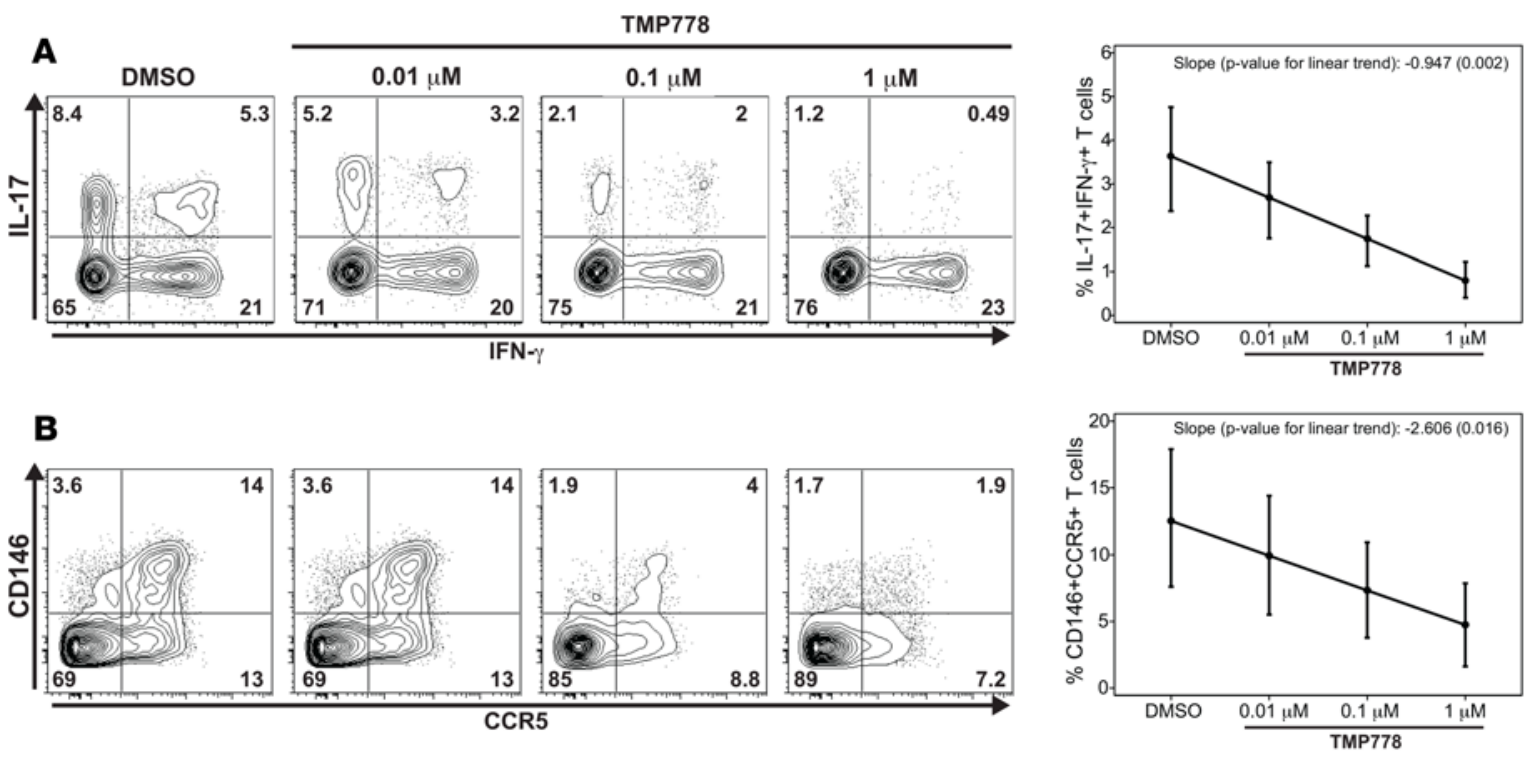

Figure 5. Effect of ROR $\gamma$ t inhibitor TMP778 on generation of Th1/Th17 cells and CD146+CCR5 ${ }^{+} \mathrm{T}$ cells among ICOS-differentiated Th17 cells. CD4 ${ }^{+} T$ cells from healthy donors were activated with anti-CD3/anti-ICOS-coated beads under Th17-polarizing conditions in the presence of indicated concentrations of TMP778 and vehicle control DMSO. After 6 days, the expression of IL-17, IFN- $\gamma$, CD14, and CCR5 on T cells were measured by flow cytometry. (A) Representative plots of IL-17 and IFN- $\gamma$ expression with mean \pm SEM values for frequency of IFN- $\gamma^{+} I L-17^{+}$T cells $(n=8)$. (B) Representative plots of CD146 and CCR5 expression with mean \pm SEM values for frequency of $\mathrm{CD}^{146}{ }^{+} \mathrm{CCR} 5^{+} \mathrm{T}$ cells $(n=5)$. Comparisons in A-B were analyzed using a 1-sample $t$ test comparing the mean linear rate of change, which was estimated for each value separately using least square estimation, to 0 .

showed that CD146-expressing T cells upregulated IL-17, IL-22, and CCR6 mRNA (44). Here, we observed in patients with active $\mathrm{CGvHD}$ an increased expression of ROR $\gamma \mathrm{t}$ within $\mathrm{CD} 146^{+}$or $\mathrm{CD} 146^{+} \mathrm{CCR} 5^{+} \mathrm{T}$ cells (Tcon and Treg), suggesting a strong Th17 signature during cGvHD. The role of CD146 in Th17 differentiation remains poorly understood; however, we previously showed using shRNA (CD146) experiments that naive CD4 T cells cultured under Th17 polarizing conditions had reduced capacity to produce IL-17 and IFN- $\gamma$ (33). We have now confirmed these data using murine naive CD146-KO T cells. Thus, CD146 expression appears as a surrogate marker for IL-17 and IFN- $\gamma$ pathogenic subset without precluding for a mechanistic role. Interestingly, CD146-expressing Treg showed a decreased suppressive capacity consistent with the upregulation of ROR $\gamma t$. This underlines the altered homeostasis between Treg and Tcon previously described (5), along with the potential impact of a defective function within regulatory subsets during cGvHD.

CCR5 is a chemokine receptor for CCL14 and CCL5, secreted at inflammatory sites, shown to promote the homing of inflammatory Teff subset, such as Th1 (45). We showed that CCR5-expressing CD4 T cells expressed greater levels of T-bet and IFN- $\gamma$. CCR5-expressing CD4 T cells have been evaluated in the context of aGvHD, but no reports investigated its implication on circulating T cells during cGvHD. Morita et al. reported the expression of CCR 5 by a lymphoid infiltrate within the skin of patients with cGvHD, suggesting its role in the migration of $\mathrm{T}$ cells toward inflammatory sites (51). Interestingly, CD146/CCR5 double-positive CD4 T cells appeared to be enriched for a subset with a mixed polarization of Th1 and Th17, as attested by the coexpression of ROR $\gamma t / \mathrm{T}$-bet and IFN- $\gamma / \mathrm{IL}-17$. This subset has been shown to harbor a pathogenic role in several autoimmune diseases $(52,53)$. Indeed, Annunziato et al. previously showed that the Th1/Th17 subset showed increased cytotoxic capacity and lower susceptibility to the Treg suppressive activity (52). Comparably, Brüggen et al. observed a mixed Th1/Th17 signature in the skin of patients with lichenoid cGvHD (32).

To understand the role of CD146-expressing $\mathrm{T}$ cells in the pathogenesis of $\mathrm{cGvHD}$, we utilized donor CD146-KO splenocytes in our multiorgan model of cGvHD with BO manifestations (46). We observed a significant alleviation of BO-cGvHD. Furthermore, we observed an increase in the pathogenic IFN- $\gamma^{+} \mathrm{IL}-17^{+}$ subset within both $\mathrm{CD} 146^{+}$and $\mathrm{CD} 146^{+} \mathrm{CCR}^{+}$fractions in the lung of animals developing $\mathrm{CGvHD}$ that was alleviated when using CD146-KO splenocytes. In our model using splenocytes from CD146-KO mice, the remaining $\mathrm{CD} 146^{+}$or $\mathrm{CD} 146^{+} \mathrm{CCR} 5^{+}$fractions, thus, appeared to differentiate from WT BM lymphoid progenitors. However, the overall decrease in $\mathrm{CD} 146^{+}$and $\mathrm{CD} 146^{+} \mathrm{CCR} 5^{+}$subsets may be consecutive to thymic injury from $\mathrm{cGvHD}$ and reduced production of $\mathrm{T}$ cells. 

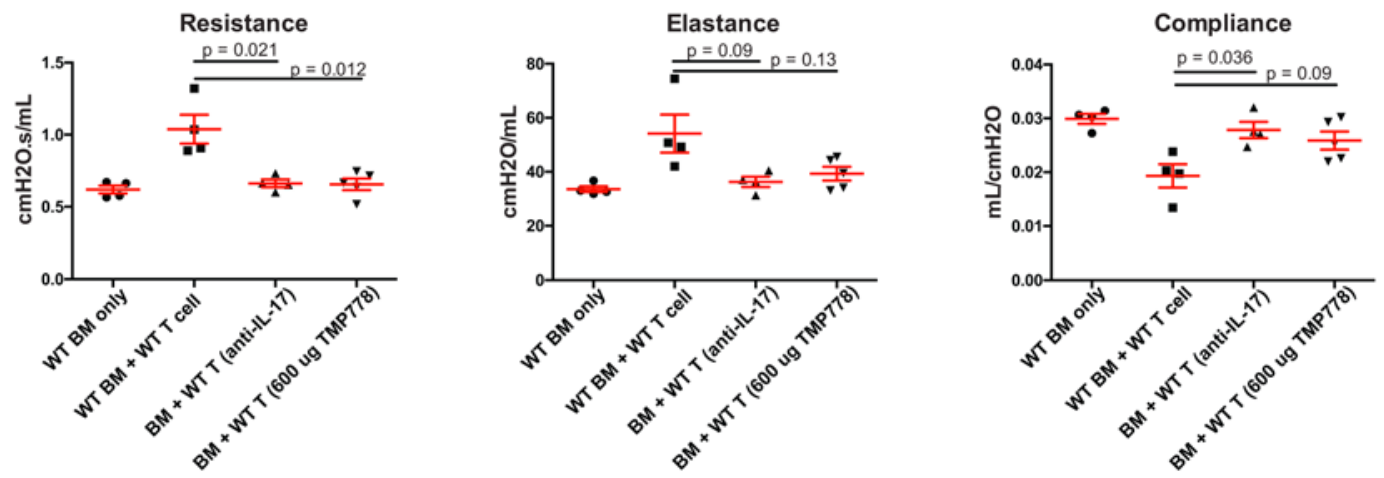

Figure 6. IL-17 blocking antibody and ROR $\gamma$ t inhibitor (TMP778) alleviates CGvHD. B10.BR mice were transplanted with WT B6 BM only or with WT B6 T cells. As indicated, cohorts of recipients receiving WT T cells received an IL-17 blocking antibody or a ROR $\gamma$ t inhibitor (TMP778) beginning on day 28 after BMT. Mice were evaluated at day 56 for pulmonary function, $n=4-7$ mice per group. Comparisons were analyzed using the Wilcoxon rank-sum test, with Bonferroni correction for multiple comparisons.

We previously showed, in this model, the requirement of alloantibody production from donor B cells differentiated during GC reaction, where TFH cells play a central role $(46,47)$. However, we didn't observe any impact on TFH and GC B cell frequencies between CD146-KO and WT splenocyte conditions. This suggests that CD146-KO does not impair T-B cross talk and B cell differentiation into GC B cells and plasmablasts. Instead, CD146-KO appears to hamper Th17 cells that harbor profibrotic functions toward lung tissue, as we and other have previously shown $(54,55)$, thus explaining the improvement of pulmonary function parameters. As we previously reported the role of macrophages in the lung fibrosis, we analyzed macrophage infiltration using immunofluorescence and showed an increased infiltrate in murine cGvHD that was alleviated in mice receiving CD146-KO splenocytes. This underlines the central role of Th17-polarized subsets, which harbor the capacity to secrete chemokines (CXCL8, CCL20, GM-CSF, IL-1 $\beta$, and $\mathrm{TNF}-\alpha$ ), thus promoting a proinflammatory environment (48).

Because the CD146-expressing subset is Th17 polarized and appears as a key player of cGvHD, we tested a small-molecule inhibitor of the ROR $\gamma \mathrm{t}$ pathway to specifically target the Th17-derived subset. TMP778 is a pharmacological inhibitor that binds to ROR $\gamma$ t to block downstream gene expression, such as IL-17A/F, IL-22, IL-23R, and CCR6, but also prevent a ROR $\gamma$ t inhibitory effect on T-bet and GATA3 gene expression (40). TMP778 suppressed IL-17 and IFN- $\gamma$ coproduction and diminished the CD146/CCR5 double-positive subset not only from differentiated Th17 in vitro (ICOS-induced), but also in an alloreactive context (MLR). Importantly, TMP778 administration to mice receiving WT splenocytes alleviated lung cGvHD. Similarly, we observed BO alleviation when using anti-IL-17 blocking antibody, partly mimicking the downstream effect of TMP778. In addition, ROR $\gamma$ t program expression is dependent on the STAT3 axis (56), as attested by reports on STAT3 deficiency $(57)$ or STAT3 inhibitors $(38,58)$ inducing ROR $\gamma \mathrm{t}$ inhibition and Th17 deficiency. Thus, we also administered Cucurbitacin I, a potent STAT3 inhibitor, to evaluate upstream ROR $\gamma \mathrm{t}$ inhibition and observed BO alleviation at a similar level to TMP778 or CD146$\mathrm{KO}$ (data not shown).

In summary, our study provides data supporting the role of CD1460-expressing CD4 T cells in the pathogenesis of $\mathrm{cGvHD}$, showing enhanced Th17 features also involved in other autoimmune diseases (44, 59). This proposed cellular biomarker of $\mathrm{cGvHD}$ would be required to be prospectively validated in order to justify clinical applications of ROR $\gamma \mathrm{t}$ inhibitors showing promising preclinical results.

\section{Methods}

Supplemental Methods are available online with this article.

Mice. C57BL/6 (B6; H2 ${ }^{\mathrm{b}}$ ) mice were purchased from the National Cancer Institute. $\mathrm{H} 2^{\mathrm{k}}$ mice were purchased from Jackson Laboratories. CD146-KO mice (on the $\mathrm{H} 2^{\mathrm{b}}$ background) were provided for this study by Hong Wei Chu (National Jewish Health, Denver, Colorado, USA). Mice were housed in a specific pathogen-free facility.

BM transplant and therapeutic interventions in mice. $\mathrm{H} 2^{\mathrm{k}}$ recipients were transplanted as previously described (31). Briefly, mice were given 2 doses of cyclophosphamide $(120 \mathrm{mg} / \mathrm{Kg})$ i.p. and total body irradiation (TBI) 
(8.3 Gy). Mice were transplanted with $1 \times 10^{7}$ WT B6 BM cells supplemented with or without $0.6 \times 10^{5}$ to 0.8 $\times 10^{5} \mathrm{~T}$ cells from either WT or CD146-KO B6, where indicated. Where specified, cGvHD recipients were given anti-IL-17 (Centocor Biopharmaceutical) i.p. (250 $\mu \mathrm{g} /$ mice, twice a week from d28-d49). TMP778, prepared as described below, was given s.c. $(600 \mu \mathrm{g} /$ mice twice daily from d28-d42). Anti-IL-17 blocking antibody $(5.1 \mathrm{mg} / \mathrm{ml})$ or isotype $(4.9 \mathrm{mg} / \mathrm{ml})$ diluted in PBS were injected i.p. twice a week for 3 weeks.

Pulmonary function tests in mice. Anesthetized mice were weighed, unblinded animals were intubated, and lung function was assessed by whole body plethysmography using the Flexivent system (SCIREQ) and analyzed using the Flexivent software version 7.3.

Flow cytometry for murine in vitro and in vivo studies. Spleens, lymph nodes, lungs, and livers were harvested for IL-17 analysis on d28, d42, and d56, and single cell suspensions were made. The cells were stimulated with Cell Stimulation Cocktail plus Protein Transport Inhibitors (eBioscience, 00-4975-93) for 5 hours at $37^{\circ} \mathrm{C}$ in complete-RPMI. Cells were stained with fixable viability dye eF780 or eF506 (eBioscience), antiCD4 (eBioscience, clone GK1.5), anti-IFN- $\gamma$ (BD Biosciences, clone XMG1.2), anti-IL-17A (eBioscience, clone eBio17B7), anti-IL-21 (eBioscience, clone FFA21), anti-ROR $\gamma \mathrm{t}$ (eBioscience, clone B2D), anti-CCR5 (eBioscience, clone HM-CCR5 [7A4]), anti-CD146 (BD Biosciences, clone ME-9F1), and anti-CD45.2 (BD Biosciences, clone 104). All cells were fixed and permeabilized by the FOXP3 Fixation/Permeabilization Concentrate and Diluent kit (eBioscience).

Frozen mouse tissue preparation. All organs harvested were embedded in OCT compound, snap frozen in liquid nitrogen, and stored in $-80^{\circ} \mathrm{C}$. Lungs were inflated by infusing $1 \mathrm{ml}$ of OCT:PBS (3:1) intratracheally prior to harvest.

Histology and trichrome staining of mouse tissues. Cryosections $(6 \mu \mathrm{m})$ were fixed for 5 minutes in acetone and stained with H\&E to determine pathology and with the Masson's trichrome staining kit (Sigma-Aldrich) for detection of collagen deposition. Histopathology scores were assigned as previously described (46). Collagen deposition was quantified on trichrome-stained sections as a ratio of area of blue staining to area of total staining using the Adobe Photoshop CS3 analysis tool. Collagen content was quantified by hydroxyproline assay (Sigma-Aldrich). Briefly, the left lobe of each mouse was homogenized in $200 \mu 1$ deionized (DI) water and then hydrolyzed in hydrochloric acid at $120^{\circ} \mathrm{C} ; 5-10 \mu 1$ of supernatant was transferred to a 96-well plate and evaporated to dryness. The amount of hydroxyproline in the lung homogenate aliquot was measured by the hydroproline assay according to the protocol (60).

Patient characteristics. Laboratory studies were performed on frozen samples from 40 patients who underwent allogeneic HSCT at the Dana-Farber Cancer Institute and Brigham and Women's Hospital (Boston, Massachusetts, USA). Clinical characteristics of these patients are summarized in Table 1. Chronic GvHD grade was established at the time of sample collection using NIH guidelines (61) and summarized in Table 1. Biological samples were collected at the onset or flare of cGvHD (70\%) or in patients with stable active cGvHD disease (30\%).

Flow cytometry for human studies. Thawed human PBMC were first stained using viability dye eF780 (eBioscience). A panel of surface markers was then used at $4^{\circ} \mathrm{C}$ for 20 minutes with fluorochrome-conjugated antibodies. The following reagents were used: CD3 (clone UCHT1), CD4 (clone SK3), CD25 (clone M-A251), CD146 (clone P1H12), and CCR5 (clone 2D7) from BD Bioscience; CD45RA (clone IMU2711) from Beckman Coulter; and CD127 (clone eBioRDR5, eBioscience). To evaluate T cell polarization, PBMC were stained using antibodies targeting intracellular antigens specific for Treg (FoxP3, clone PCH101, eBioscience), Th1 (T-bet, clone 4B10, BioLegend), and Th17 (ROR $\gamma$ t, clone Q21-559, BD Biosciences) with the FoxP3/Transcription Factor Staining kit (eBioscience). For cytokine flow cytometry, PBMC were stimulated with PMA $(50 \mathrm{ng} / \mathrm{ml})$ ionomycin $(1 \mu \mathrm{M})$ (Sigma-Aldrich) in the presence of Brefeldin A (BD Biosciences) for 5 hours in RPMI1640, supplemented with 10\% FBS, L-glutamine, and pencilline/streptamycine. Cells were then fixed and permeabilized with BD Cytofix/Cytoperm kit and stained with cytokine-specific antibodies: IFN- $\gamma$ (clone B27) from BD Biosciences and IL-17 (clone eBio64Dec17) from eBioscience. Flow cytometry standards and quality controls were run regularly to ensure stability of the analytical instruments. A minimum of 150,000 events were recorded in the lymphocyte gate. Cells were analyzed using LSR Fortessa (BD Biosciences) and FlowJo v.10 software (Tree Star Inc.). For Treg suppression assay: PBMC from leukopacks (HDs) were enriched for $\mathrm{CD}^{+} \mathrm{T}$ cells (MACS-negative selection) and stained with CD4, CD25, CD127, and CD146. The following subsets were sorted using the FACSAria (BD Bioscience): Tcon (CD8 $\left.{ }^{-} \mathrm{CD} 14^{-} \mathrm{CD} 19^{-} \mathrm{CD} 4^{+} \mathrm{CD} 25^{-} \mathrm{CD} 127^{+}\right)$, Treg $\mathrm{CD} 146^{+}\left(\mathrm{CD}^{-} \mathrm{CD} 14^{-} \mathrm{CD} 19^{-} \mathrm{CD} 4^{+} \mathrm{C}-\right.$ $\left.\mathrm{D} 25^{\mathrm{hi}} \mathrm{CD} 127^{-} \mathrm{CD} 146^{+}\right)$, and Treg CD146- $\left(\mathrm{CD} 8^{-} \mathrm{CD} 14^{-} \mathrm{CD} 19^{-} \mathrm{CD} 4^{+} \mathrm{CD} 25^{\mathrm{hi}} \mathrm{CD} 12^{-} \mathrm{CD} 146^{-}\right)$. Purity of sort- 
ed subsets was $>95 \%$. Tcon were stained with CFSE $(1 \mu \mathrm{M})$. Treg and Tcon subsets were cocultured for 5 days at different ratios upon stimulation with coated $\alpha \mathrm{CD} 3$ (final concentration $[\mathrm{Cf}]=5 \mu \mathrm{g} / \mathrm{ml}$ ) and soluble $\alpha \mathrm{CD} 28(\mathrm{Cf}=3 \mu \mathrm{g} / \mathrm{ml})$. At $\mathrm{d} 5$, cells were stained with a viability dye and read on Fortessa. For suppression, formula $=($ Tcon alone $-[$ Tcon + Treg $]) /($ Tcon alone $) \times 100$.

ROR $\gamma$ t and IL-17 targeting reagents. TMP778 powder, synthesized by GlaxoSmithKline and provided by Jianfei Yang (Tempero Pharmaceuticals a company of GSK, Cambridge, Massachusetts, USA), was dissolved in DMSO at $808.76 \mathrm{mM}$ and stored at $-80^{\circ} \mathrm{C}$ as aliquots. Immediately before use, an aliquot of TMP778 stock solution was diluted in DMSO to $0.01 \mathrm{mM}, 0.1 \mathrm{mM}$, and $1 \mathrm{mM}$ and then further diluted by a factor of 1,000 in culture medium to final concentrations of $0.01 \mu \mathrm{M}, 0.1 \mu \mathrm{M}$, and $1 \mu \mathrm{M}$, respectively. DMSO at $0.1 \%$ was used as vehicle control. For in vitro treatment, PBMCs were prepared from leukopacks of HD (Central Indiana Blood Bank) by Ficoll-Paque density-grade centrifugation (GE Healthcare). Total CD4 T cells were positively isolated using human CD4 microbeads (Miltenyi Biotec) and activated for 6 days with anti-CD3/anti-ICOS antibody-coated Dynabeads M-450 Tosylactivated (Invitrogen) at a bead/cell ratio of 1:5 under the Th17-polarizing conditions: IL-1 $\beta$ (20 ng/ml), IL-6 (30 ng/ml), IL-23 (30 ng/ml), TGF- $\beta$ ( $2 \mathrm{ng} / \mathrm{ml})$, and neutralizing antibodies against IL-4 $(5 \mu \mathrm{g} / \mathrm{ml})$ and IFN- $\gamma(2 \mu \mathrm{g} / \mathrm{ml})$ (eBioscience). Exposure to differentiating cytokines (all from R\&D Systems) and blocking antibodies was maintained throughout the culture period. For allogeneic MLR, irradiated (3,000 cGy) PBMCs from one donor were used as the stimulator and mixed in a 1:1 ratio with PBMCs from another donor, used as the responder for 8-10 days. TMP778 or DMSO vehicle control was added to the Th17 and MLR cultures on d0, replenished every 3 days, and maintained throughout the culture period. TMP778-treated Th17 or MLR cells were analyzed by flow cytometry for cell-surface expression of CD4, CD146, and CCR5. For intracellular cytokine staining of IL-17 and IFN- $\gamma$, cells were stimulated with PMA (50 ng/ml; Sigma-Aldrich), ionomycin ( $1 \mu \mathrm{g} / \mathrm{ml}$; Sigma-Aldrich), and brefeldin A ( $3 \mu \mathrm{g} / \mathrm{ml})$ (eBioscience) for 5 hours. Intracellular cytokines were stained with the intracellular fixation and permeabilization buffer set (eBioscience). All staining antibodies were obtained from eBioscience. Stained cells were analyzed using an Attune Flow Cytometer (Invitrogen) and FlowJo software.

Statistics. Baseline clinical characteristics were compared between groups using either Fisher's exact test or $\chi^{2}$ test for categorical variables or Wilcoxon rank-sum test for continuous variables. Phenotypic and functional data were compared using Wilcoxon rank-sum test for unpaired group comparison and Wilcoxon signed-rank test for paired comparison. Prior to analysis, the normality assumption was examined. All tests were 2 -sided at the significance level of 0.05 . For Figure 6, each subplot involved 2 groupwise comparisons. To account for the type I error inflation due to multiple comparisons, we applied the Bonferroni correction. For Figure 5 and Supplemental Figure 6, we evaluated the mean linear rate of change of IL- $17^{+} \mathrm{IFN}^{+}$and $\mathrm{CD}_{146}{ }^{+} \mathrm{CCR} 5^{+}$as a function of different concentrations of a ROR $\gamma \mathrm{t}$ inhibitor, TMP778 (from $0-1 \mu \mathrm{M}$ ). To statistically evaluate this change, we performed a 1-sample $t$ test comparing the mean linear rate of change (e.g., slope), which was estimated for each value separately using least square estimation, to 0 .

Statistical analyses and graphs for Figures 1-4 were performed using Prism software (GraphPad), and data are presented as mean \pm SEM. Statistical analyses for Figures 5 and 6 and Supplemental Figure 6 were performed using STATA 14 for Windows.

Study approval. All studies were conducted in accordance with the GSK Policy on the Care, Welfare, and Treatment of Laboratory Animals and were reviewed by the University of Minnesota institutional animal care and use committee (IACUC 1504-32476A) and by Indiana University (IACUC 10488). All patients and HDs were enrolled in clinical research protocols approved by the Human Subjects Protection Committee of the Dana-Farber/Harvard Cancer Center (IRB 01-206). Written informed consent was obtained prior to sample collection, in accordance with the Declaration of Helsinki. The human biological samples were sourced ethically, and their research use was in accord with the terms of the informed consents.

\section{Author contributions}

EF, KP, RF, BG, TA, WL, LL, GB, DJ, ELE, and JD performed experiments, analyzed data, and participated in manuscript preparation. HWC provided CD146-KO mice. ML and JY provided TMP778 and edited the manuscript. DSW, PB, KG, GRH, and KPAM participated in study design and manuscript preparation. CSC, JHA, and RJS provided human samples and assisted in manuscript preparation. JR, SP, and BRB participated in study design and manuscript preparation and obtained funding for the study. JSS participated in study design and manuscript preparation. JK provided human samples and assisted in manuscript preparation. 


\section{Acknowledgments}

This work was supported by the NIH (R01 CA168814, R01 CA183559, R01 CA183560, P01 CA142106, P01 AI056299), the Leukemia \& Lymphoma Society Scholar Award (1293-15), the Lilly Physician Scientist Initiative Award, Cancer Biology Training grant T32 CA009138, the Ted and Eileen Pasquarello Research Fund, the MD-PhD program (University Hospital of Bordeaux, France), and the French Society of Hematology (SFH) and Association Laurette Fugain. Immunofluorescence imaging was provided by the University of Minnesota - University Imaging Centers, http://uic.umn.edu.

Address correspondence to: Bruce R. Blazar, Department of Pediatrics, Masonic Cancer Center, University of Minnesota, 420 Delaware Strett SE, MMC 109, Minneapolis, Minnesota 55455, USA. Phone: 612.626.2734; Email: blaza001@umn.edu. Or to: Sophie Paczesny, Indiana University School of Medicine, 1044 W. Walnut Street, Room R4-425, Indianapolis, Indiana 46202, USA. Phone: 317.278.5487; Email: sophpacz@iu.edu.

1. Lee SJ, Vogelsang G, Flowers ME. Chronic graft-versus-host disease. Biol Blood Marrow Transplant. 2003;9(4):215-233.

2. Socié G, Ritz J. Current issues in chronic graft-versus-host disease. Blood. 2014;124(3):374-384.

3. Paczesny S. Discovery and validation of graft-versus-host disease biomarkers. Blood. 2013;121(4):585-594.

4. Paczesny S, et al. National Institutes of Health Consensus Development Project on Criteria for Clinical Trials in Chronic Graftversus-Host Disease: III. The 2014 Biomarker Working Group Report. Biol Blood Marrow Transplant. 2015;21(5):780-792.

5. Matsuoka K, et al. Altered regulatory $\mathrm{T}$ cell homeostasis in patients with CD4+ lymphopenia following allogeneic hematopoietic stem cell transplantation. J Clin Invest. 2010;120(5):1479-1493.

6. Sarantopoulos S, et al. Altered B-cell homeostasis and excess BAFF in human chronic graft-versus-host disease. Blood. 2009;113(16):3865-3874.

7. Yu J, et al. Biomarker Panel for Chronic Graft-Versus-Host Disease. J Clin Oncol. 2016;34(22):2583-2590.

8. Coghill JM, Sarantopoulos S, Moran TP, Murphy WJ, Blazar BR, Serody JS. Effector CD4+ T cells, the cytokines they generate, and GVHD: something old and something new. Blood. 2011;117(12):3268-3276.

9. Cooke KR, et al. The Biology of Chronic Graft-versus-Host Disease: A Task Force Report from the National Institutes of Health Consensus Development Project on Criteria for Clinical Trials in Chronic Graft-versus-Host Disease. Biol Blood Marrow Transplant. 2017;23(2):211-234.

10. Koreth J, et al. Efficacy, durability, and response predictors of low-dose interleukin-2 therapy for chronic graft-versus-host disease. Blood. 2016;128(1):130-137.

11. Allen JL, et al. B cells from patients with chronic GVHD are activated and primed for survival via BAFF-mediated pathways. Blood. 2012;120(12):2529-2536.

12. Dubovsky JA, et al. Ibrutinib treatment ameliorates murine chronic graft-versus-host disease. J Clin Invest. 2014;124(11):4867-4876.

13. Flynn R, et al. Targeting Syk-activated B cells in murine and human chronic graft-versus-host disease. Blood. 2015;125(26):4085-4094.

14. Sarantopoulos S, et al. Recovery of B-cell homeostasis after rituximab in chronic graft-versus-host disease. Blood. 2011;117(7):2275-2283.

15. DuPage M, Bluestone JA. Harnessing the plasticity of CD4(+) T cells to treat immune-mediated disease. Nat Rev Immunol. 2016;16(3):149-163.

16. Ivanov II, et al. The orphan nuclear receptor RORgammat directs the differentiation program of proinflammatory IL-17+ T helper cells. Cell. 2006;126(6):1121-1133.

17. Annunziato F, Cosmi L, Liotta F, Maggi E, Romagnani S. Defining the human T helper 17 cell phenotype. Trends Immunol. 2012;33(10):505-512.

18. Wang C, et al. CD5L/AIM Regulates Lipid Biosynthesis and Restrains Th17 Cell Pathogenicity. Cell. 2015;163(6):1413-1427.

19. Furlan SN, et al. Systems analysis uncovers inflammatory Th/Tc17-driven modules during acute GVHD in monkey and human T cells. Blood. 2016;128(21):2568-2579.

20. Serody JS, Hill GR. The IL-17 differentiation pathway and its role in transplant outcome. Biol Blood Marrow Transplant. 2012;18(1 Suppl):S56-S61.

21. Kappel LW, et al. IL-17 contributes to CD4-mediated graft-versus-host disease. Blood. 2009;113(4):945-952.

22. Yi T, et al. Absence of donor Th17 leads to augmented Th1 differentiation and exacerbated acute graft-versus-host disease. Blood. 2008;112(5):2101-2110.

23. Dander E, et al. Interleukin-17-producing T-helper cells as new potential player mediating graft-versus-host disease in patients undergoing allogeneic stem-cell transplantation. Transplantation. 2009;88(11):1261-1272.

24. Broady R, et al. Cutaneous GVHD is associated with the expansion of tissue-localized Th1 and not Th17 cells. Blood. 2010;116(25):5748-5751.

25. Ratajczak P, et al. Th17/Treg ratio in human graft-versus-host disease. Blood. 2010;116(7):1165-1171.

26. Chen X, Vodanovic-Jankovic S, Johnson B, Keller M, Komorowski R, Drobyski WR. Absence of regulatory T-cell control of TH1 and TH17 cells is responsible for the autoimmune-mediated pathology in chronic graft-versus-host disease. Blood. 2007;110(10):3804-3813.

27. Carlson MJ, West ML, Coghill JM, Panoskaltsis-Mortari A, Blazar BR, Serody JS. In vitro-differentiated TH17 cells mediate lethal acute graft-versus-host disease with severe cutaneous and pulmonary pathologic manifestations. Blood. 2009;113(6):1365-1374.

28. Hill GR, et al. Stem cell mobilization with G-CSF induces type 17 differentiation and promotes scleroderma. Blood. 2010;116(5):819-828. 
29. Alexander KA, et al. CSF-1-dependant donor-derived macrophages mediate chronic graft-versus-host disease. J Clin Invest. 2014;124(10):4266-4280.

30. Radojcic V, et al. STAT3 signaling in CD4+ T cells is critical for the pathogenesis of chronic sclerodermatous graft-versus-host disease in a murine model. J Immunol. 2010;184(2):764-774.

31. Flynn R, et al. Targeted Rho-associated kinase 2 inhibition suppresses murine and human chronic GVHD through a Stat3-dependent mechanism. Blood. 2016;127(17):2144-2154.

32. Brüggen MC, et al. Diverse T-cell responses characterize the different manifestations of cutaneous graft-versus-host disease. Blood. 2014;123(2):290-299.

33. Li W, et al. Proteomics analysis reveals a Th17-prone cell population in presymptomatic graft-versus-host disease. JCI Insight. 2016;1(6):e86660

34. Baeten D, et al. Secukinumab, an Interleukin-17A Inhibitor, in Ankylosing Spondylitis. NEngl J Med. 2015;373(26):2534-2548

35. Langley RG, et al. Secukinumab in plaque psoriasis--results of two phase 3 trials. N Engl J Med. 2014;371(4):326-338.

36. Sandborn WJ, et al. Ustekinumab induction and maintenance therapy in refractory Crohn's disease. NEngl J Med. 2012;367(16):1519-1528.

37. Weiss JM, et al. ROCK2 signaling is required to induce a subset of T follicular helper cells through opposing effects on STATs in autoimmune settings. Sci Signal. 2016;9(437):ra73.

38. Zanin-Zhorov A, et al. Selective oral ROCK2 inhibitor down-regulates IL-21 and IL-17 secretion in human T cells via STAT3-dependent mechanism. Proc Natl Acad Sci USA. 2014;111(47):16814-16819.

39. Patel DD, Lee DM, Kolbinger F, Antoni C. Effect of IL-17A blockade with secukinumab in autoimmune diseases. Ann Rheum Dis. 2013;72 Suppl 2:ii116-ii123.

40. Xiao S, et al. Small-molecule ROR $\gamma$ t antagonists inhibit T helper 17 cell transcriptional network by divergent mechanisms. Immunity. 2014;40(4):477-489

41. Skepner J, et al. Pharmacologic inhibition of ROR $\gamma$ t regulates Th17 signature gene expression and suppresses cutaneous inflammation in vivo. J Immunol. 2014;192(6):2564-2575.

42. Kunkel EJ, Butcher EC. Chemokines and the tissue-specific migration of lymphocytes. Immunity. 2002;16(1):1-4.

43. Guezguez B, Vigneron P, Lamerant N, Kieda C, Jaffredo T, Dunon D. Dual role of melanoma cell adhesion molecule (MCAM)/CD146 in lymphocyte endothelium interaction: MCAM/CD146 promotes rolling via microvilli induction in lymphocyte and is an endothelial adhesion receptor. J Immunol. 2007;179(10):6673-6685.

44. Dagur PK, et al. MCAM-expressing CD4(+) T cells in peripheral blood secrete IL-17A and are significantly elevated in inflammatory autoimmune diseases. J Autoimmun. 2011;37(4):319-327.

45. Loetscher P, et al. CCR5 is characteristic of Th1 lymphocytes. Nature. 1998;391(6665):344-345.

46. Srinivasan M, et al. Donor B-cell alloantibody deposition and germinal center formation are required for the development of murine chronic GVHD and bronchiolitis obliterans. Blood. 2012;119(6):1570-1580.

47. Flynn R, et al. Increased $\mathrm{T}$ follicular helper cells and germinal center B cells are required for cGVHD and bronchiolitis obliter ans. Blood. 2014;123(25):3988-3998.

48. Fan L, et al. Neutralizing IL-17 prevents obliterative bronchiolitis in murine orthotopic lung transplantation. Am J Transplant. 2011;11(5):911-922.

49. Paulos CM, et al. The inducible costimulator (ICOS) is critical for the development of human T(H)17 cells. Sci Transl Med 2010;2(55):55ra78.

50. Dagur PK, McCoy JP. Endothelial-binding, proinflammatory T cells identified by MCAM (CD146) expression: Characterization and role in human autoimmune diseases. Autoimmun Rev. 2015;14(5):415-422.

51. Morita NI, Matsumura Y, Morita K, Miyachi Y. Expression of CCR5 in graft-versus-host disease (GVHD) of the skin: immunohistochemical staining of 38 cases. J Dermatol. 2007;34(4):254-257.

52. Annunziato F, et al. Phenotypic and functional features of human Th17 cells. J Exp Med. 2007;204(8):1849-1861.

53. Nistala K, et al. Th17 plasticity in human autoimmune arthritis is driven by the inflammatory environment. Proc Natl Acad Sci USA. 2010;107(33):14751-14756.

54. Nishimori H, et al. Synthetic retinoid Am80 ameliorates chronic graft-versus-host disease by down-regulating Th1 and Th17. Blood. 2012;119(1):285-295.

55. Burlingham WJ, et al. IL-17-dependent cellular immunity to collagen type V predisposes to obliterative bronchiolitis in human lung transplants. J Clin Invest. 2007;117(11):3498-3506.

56. Harris TJ, et al. Cutting edge: An in vivo requirement for STAT3 signaling in TH17 development and TH17-dependent autoimmunity. J Immunol. 2007;179(7):4313-4317.

57. Ma CS, et al. Deficiency of Th17 cells in hyper IgE syndrome due to mutations in STAT3. J Exp Med. 2008;205(7):1551-1557.

58. Park JS, et al. STA-21, a promising STAT-3 inhibitor that reciprocally regulates Th17 and Treg cells, inhibits osteoclastogenesis in mice and humans and alleviates autoimmune inflammation in an experimental model of rheumatoid arthritis. Arthritis Rheumatol. 2014;66(4):918-929.

59. Wu C, Goodall JC, Busch R, Gaston JS. Relationship of CD146 expression to secretion of interleukin (IL)-17, IL-22 and interferon- $\gamma$ by CD4(+) T cells in patients with inflammatory arthritis. Clin Exp Immunol. 2015;179(3):378-391.

60. Panoskaltsis-Mortari A, Tram KV, Price AP, Wendt CH, Blazar BR. A new murine model for bronchiolitis obliterans post-bone marrow transplant. Am J Respir Crit Care Med. 2007;176(7):713-723.

61. Jagasia MH, et al. National Institutes of Health Consensus Development Project on Criteria for Clinical Trials in Chronic Graft-versus-Host Disease: I. The 2014 Diagnosis and Staging Working Group report. Biol Blood Marrow Transplant. 2015;21(3):389-401.e1. 